\title{
Cooperação e competição na Zona Euro: o futuro das reformas da governança económica da União Europeia ${ }^{\dagger}$
}

\author{
Gabriele De Angelis* \\ * Instituto de Filosofia da Nova Universidade Nova de Lisboa, Portugal; gabriele.deangelis@fcsh.unl.pt
}

\begin{abstract}
Resumo
A construção da moeda única apresenta falhas ao nível dos mecanismos que deveriam garantir a convergência macroeconómica entre os países membros da União Europeia. Menos conhecidas e analisadas são as falhas na construção política, ou seja, na estrutura de gestão e tomada de decisões: uma estrutura cujo sistema de incentivos faz para que não exista um interesse comum na estabilização dos desequilíbrios macroeconómicos entre os Estados-membros, e que por isso põe em risco a estabilidade a médio prazo da zona euro. Duas são as possíveis soluções ao nível da estrutura política: uma "união política", isto é, uma maior integração que inclua mecanismos supranacionais de legitimidade democrática, ou uma diferente estrutura de regras no contexto da governança atual, que crie um interesse comum na estabilização da moeda única. O artigo expõe estas duas opções, analisa as propostas da Comissão perante estas duas perspetivas, e avalia os obstáculos no caminho das reformas de um ponto de vista das preferências dos governos dos mais influentes países membros.

Palavras-chave: Euro; governança económica; legitimidade política; reformas institucionais; União Económica e Monetária da União Europeia
\end{abstract}

\begin{abstract}
Notoriously, the fiscal architecture of the common currency was flawed in several respects from the very start. Less well known are the flaws in the political architecture of the Economic and Monetary Union. This is characterised by a system of incentives that thwarts all efforts towards an overall macro-economic stabilisation of the Eurozone. There are two possible solutions to this problem: one is the political union, to be brought about by means of an additional transfer of economic and fiscal sovereignty and a corresponding mechanism of political legitimacy, or different fiscal rules within the current structure of political governance. The essay expounds upon these two options while taking into account the European Commission's most recent reform proposals. It furthermore assesses the hurdles that the latter will have to overcome against the background of the preferences of the most influential Member States.
\end{abstract}

Keywords: Economic and Monetary Union of the European Union; economic governance; Euro; institutional reforms; political legitimacy 


\section{Introdução}

Passada a fase aguda da crise do euro e da dívida soberana, continua a discussão sobre as reformas da estrutura da governança da União Económica e Monetária (UEM), da estabilização da zona euro, e dos conflitos de visão e de interesse político e económico entre os países membros. Dois modelos são discutidos. O primeiro visa a continuação e o reforço da estrutura atual da governança, alicerçada num sistema de regras num contexto intergovernamental, com o objetivo de limitar as "externalidades" da indisciplina fiscal dos estados membros: num contexto institucional em que as consequências das ações de um estado membro se estendem a todos os outros, o controlo recíproco torna-se numa necessidade estrutural. O segundo modelo visa aprofundar a corresponsabilidade dos estados membros para a economia e o equilíbrio da zona euro no seu conjunto através da partilha dos riscos macroeconómicos, por um lado, e, por outro lado, de uma estrutura da governança mais atenta à legitimidade política e democrática das decisões comuns. Na base destas duas visões estão interpretações diferentes e opostas da origem da crise.

O primeiro objetivo do presente artigo consiste, portanto, no esclarecimento destas duas diferentes narrativas. Para além das conhecidas falhas no paradigma macroeconómico em que está assente a UEM desde o Tratado de Maastricht, o resultado desta primeira análise aponta para dois problemas inerentes às regras económicas e à estrutura política e da UEM. O primeiro problema consiste no facto de que as regras económicas promovem uma competição entre economias nacionais, cuja consequência é dividir os estados membros em exportadores e importadores e, portanto, em credores e devedores. Pelo contrário, a estabilidade e a sustentabilidade da zona euro precisam de um modelo de cooperação que promova ativamente um equilíbrio no fluxo de capitais e nas balanças corrente a longo prazo entre os estados membros. $\mathrm{O}$ segundo problema inerente à atual estrutura da governança económica consiste no sistema de incentivos que esta põe aos atores políticos nacionais: incentivos que motivam uma gestão conflituosa e não cooperativa da zona euro ao nível político, para além do nível económico. A estrutura atual não favorece a necessária corresponsabilidade pelas externalidades das decisões políticas dos estados membros, ou seja, faz isso num sentido muito limitado, na medida em que gere os riscos de défice ou de dívida excessiva, mas não prevê qualquer mecanismo que limite outros tipos, também relevantes, de externalidade de decisões que impactam no equilíbrio macroeconómico da zona euro.

O segundo objetivo do presente artigo é, portanto, ilustrar em que medida o sistema atual é assente numa lógica de competição entre economias nacionais e a necessidade duma gestão cooperativa dos desequilíbrios macroeconómicos. A este propósito, o artigo expõe as falhas na estrutura politica da zona euro, para além das conhecidas falhas no sistema das regras macroeconómicas.

As instituições europeias identificaram o problema da falta de cooperação macroeconómica entre os estados membros logo numa fase inicial da crise, nomeadamente no assim-chamado Relatório dos quatro presidentes, apresentado pelo 
então Presidente do Conselho Europeu, Herman Van Rompuy ${ }^{[1]}$. É só nos últimos anos, porém, que a Comissão tem vindo a formular hipóteses concretas de cooperação orçamental. O presente artigo ilustra em particular um esquema específico de cooperação orçamental ao nível dos estados membros que visa gerir o défice (ou o superavit) agregado da zona euro. Um tal esquema apresenta a vantagem de poder ser implementado através de um sistema de governança assente em regras, e por isso mais parecido com o sistema atual, menos sujeito às resistências políticas que uma reforma mais profunda da arquitetura da UEM encontraria, e menos exposto à discrição de juízo político que caracterizaria outros modelos de reforma da governança (como por exemplo uma parlamentarização da zona euro ou um acrescido papel do Parlamento Europeu na gestão de um orçamento comum) - uma discrição que os defensores da governança baseada em regras receiam. Mesmo que o esquema de coordenação orçamental não altere, portanto, a arquitetura política atual, esse desativa algumas das razões fundamentais de competição económica entre os estados membros e, por isso, promete também aliviar a competição política no seio dos órgãos europeus. Um tal esquema apresenta, contudo, alguns limites, na medida em que a coordenação orçamental possa não ser, por si só, um instrumento suficientemente forte para a redução dos desequilíbrios macroeconómicos.

\section{O euro e a crise: uma competição de narrativas}

O facto de a construção da moeda comum apresentar falhas estruturais não é geralmente contestado. Contestada é a natureza das suas falhas. Na década de 1990, a introdução da moeda única foi marcada por uma controvérsia acerca da sua construção política e institucional ${ }^{[2]}$. Da mesma forma, a crise da dívida soberana do princípio da década de 2010 foi marcada por uma acesa controvérsia acerca das suas origens e razões. Nos dois casos debateu-se o mesmo assunto, ou seja, o equilíbrio a alcançar entre estabilidade monetária, e por isso disciplina fiscal, e crescimento, ou seja, flexibilidade na política fiscal em relação ao ciclo económico. Não surpreende, portanto, que a crise da dívida soberana e a subsequente necessidade de reformar a governança económica europeia sejam marcadas por duas narrativas diferentes que, simplificando, poder-se-iam apelar de "pró-austeridade" e "anti-austeridade". As duas narrativas são assentes em duas visões diferentes da UEM e dão origem, grosso modo, a duas teorias diferentes acerca das suas falhas estruturais e das eventuais soluções.

A visão que acompanha a narrativa da austeridade interpreta a União como a convergência de interesses de estados soberanos que perseguem objetivos político-económicos diferentes e que, enquanto partilham uma responsabilidade limitada

1. Rompuy, H. (2012, December 5). Towards a Genuine Economic and Monetary Union. In collaboration with José Manuel Barroso, Jean-Claude Juncker, Mario Draghi. Brussels, Belgium: European Council.

2. Veja-se, na pluralidade de produtos de literatura científica, Godley, W. (1997), The Hole in the Treaty, in J. Shahin \& M. Wintle (ed.), The Idea of a United Europe. Political, Economic and Cultural Integration since the Fall of the Berlin Wall (pp. 174-177). Houndsmill and London: Macmillan, assim como Feldstein, M. (1992). The Case Against EMU. The Economist, 13, 23-26. 
às condições de estabilidade monetária, entretêm, pelo resto, relações de competição entre economias nacionais. As políticas de disciplina orçamental que esta narrativa sugere são uma consequência da sua visão política tout court. ${ }^{[3]}$

Pelo contrário, embora se acompanhe de forma ocasional com visões federalistas da União, a narrativa "anti-austeridade" não se esposa necessariamente com uma visão política específica, mas implica conclusões diferentes acerca da responsabilidade comum que advém da simples existência da UEM e, por conseguinte, das políticas económicas a prosseguir. As duas teorias e as respetivas visões são apresentadas de seguida.

\section{3. “Austeridade": uma União de competição económica e assimetria política}

A narrativa pró-austeridade aponta para a indisciplina fiscal (conhecida no dia a dia do debate político como "viver acima dos próprios meios") como causa da crise da dívida soberana ${ }^{[4]}$. A indisciplina fiscal seria originada por um sistema de incentivos errados na gestão da coordenação orçamental no seio da UEM: na ausência de relações de câmbio entre as moedas, os governos teriam perdido as referências ao estado da competitividade da própria economia (normalmente assinalado pelo valor da própria moeda), e teriam por isso posposto as necessárias reformas estruturais. Por conseguinte, as divergências económicas na zona euro teriam aumentado em vez de se reduzir, como se esperava da introdução da moeda comum (Tilford, 2010). Foram estas divergências a contribuir a insustentabilidade da dívida dos países que tiveram de recorrer à ajuda financeira dos parceiros.

Nesta - em si muito simples - interpretação da crise da dívida soberana espelha-se uma mais abrangente interpretação do sentido geral e dos objetivos últimos, ou seja, da finalité, da UEM. O desenho institucional da moeda comum reflete a necessidade de desincentivar o free riding, o "parasitismo" dos que entregam a estabilidade monetária às virtudes fiscais dos parceiros praticando por si uma indisciplina fiscal funcional aos próprios objetivos económicos ou políticos. A legislação pública e os seus reflexos ou pressupostos fiscais produzem efeitos sobre o preço da moeda através da inflação, do valor da dívida, do crescimento e, finalmente, da taxa de juros. Numa União monetária na qual a soberania fiscal se mantém ao nível dos estados membros, os efeitos da conduta de cada um refletem-se no valor da moeda de todos

3. László Andor oferece uma síntese eficaz das diferentes interpretações, e da relativa falta de clareza, do conceito de "austeridade". Pelos efeitos do presente artigo, "austeridade" é uma política de recuperação económica atuada em condições de crise de liquidez financeira e baseada na redução do défice, das despesas públicas, e num conjunto de reformas que têm por objetivo o aumento da competitividade externa da economia nacional. Contudo, a palavra é utilizada em virtude da sua circulação, não do seu poder explicativo. Veja-se Andor, L. (2018). Austerity: From Outrage to Progressive Alternatives. Social Europe. $<$ https://www.socialeurope.eu/austerity-outrage-progressive-alternatives $>$ [acedido a 15.02.2018].

4. Uma ótima perspetiva sobre a cética "standard view" acerca dos efeitos da moeda única antes da crise é oferecida pelo "segundo manifesto dos economistas": Kosters, W., Neumann, M., Ohr, R. \& Vaubel, R. (1998, February 9). Zweites Manifest der Euroskeptiker. Frankfurter Allgemeine Zeitung. Veja-se, para os períodos a seguir, Baimbridge, M., Burkitt, B \& Whymann, B. (2012). The Eurozone as a flawed currency area. The Political Quarterly, 83(1), 96-107. 
os outros. Por isso, a arquitetura da moeda comum foi focada desde o princípio sobre a limitação das externalidades do comportamento fiscal dos estados membros, o que implicou a limitação da soberania fiscal nacional através do controlo recíproco, cujo agente e avaliador técnico é a Comissão Europeia e cujo juiz coletivo é o Conselho. Os critérios de convergência do Tratado de Maastricht visavam portanto uniformizar a taxa de inflação (que havia de se manter próxima, ou seja dentro de uma banda de oscilação de $1.5 \%$, da dos três países com os resultados melhores em termos de estabilidade dos preços), o défice público (que havia de se manter abaixo de um limiar de $3 \%$, que definia o défice excessivo), a dívida pública (que havia de se manter abaixo do limiar do $60 \%$ do PIB ou, caso ultrapassasse esse limiar, de se encontrar num estável e adequado caminho de redução), a taxa de câmbio das moedas (que havia de se manter adentro da oscilação prevista pelo Sistema Monetário Europeu durante pelo menos dois anos), e a taxa de juros a longo prazo ${ }^{[5]}$. A primeira fase da fiscalização dizia respeito à adesão à moeda comum, enquanto as sucessivas focavam-se sobre o mantimento dos critérios de estabilidade.

Uma tal configuração institucional da moeda comum tem duas principais consequências político-económicas: a primeira é que, por falta de instrumentos de coordenação macroeconómica, a convergência das economias dos estados membros é entregue às políticas de cada um, e especialmente às suas políticas fiscais e laborais e aos respetivos impactos sobre a inflação.

A segunda consequência diz respeito à configuração das relações institucionais e políticas que uma tal arquitetura cria no concerto europeu. Sendo a política fiscal nacional o foco da fiscalização, a dialética institucional que se desenvolve vê os países membros menos "virtuosos" opostos à Comissão na avaliação das próprias políticas fiscais numa atitude de negociação permanente da própria margem de autonomia orçamental. Por outro lado, no seio do Conselho, os países fiscalmente "virtuosos" têm uma clara vantagem negocial para com os países menos virtuosos, pelo que, especialmente num momento de crise, os primeiros podem vestir as vestes de juiz perante os segundos. Assim, a diferente posição das economias nacionais transforma-se numa diferente posição de força política entre os países membros.

De forma coerente com esta estrutura institucional, a narrativa da austeridade interpreta a "divergência", ou seja, os desequilíbrios macroeconómicos que caracterizaram a década que seguiu à introdução da moeda comum, como consequência e responsabilidade exclusiva dos países em crise orçamental, prescrevendo uma mais rija disciplina e um reforço dos mecanismos de fiscalização através de uma transferência adicional de soberania fiscal. A mesma narrativa visará fiscalizar de forma muito menor os outros tipos de desequilíbrio macroeconómico, e especialmente os causados pelos países fiscalmente integres, nomeadamente os avanços na balança corrente ${ }^{[6]}$.

5. European Union (1992). Treaty on European Union, Article 109j (No.C191). Maastricht, Netherlands: Official Journal of the European Communities.

6. Veja-se a lista completa dos indicadores em Eurostat, <http://ec.europa.eu/eurostat/web/macroeconomic-imbalances-procedure/indicators $>$ [acedido a 30.3.2018]. 
As reformas da União Económica e Monetária que se seguiram a partir de 2011, depois dos resgates de Grécia, Irlanda, Portugal e do sistema bancário espanhol terem aliviado a fase aguda da crise da dívida soberana, visaram, portanto, reforçar a fiscalização orçamental dos países membros. As alterações introduzidas reconheciam as insuficiências no desenho do Pacto de Estabilidade em dois sentidos: na sua capacidade de implementação e nos seus efeitos pró-cíclicos. As mesmas eram articuladas dentro da sua lógica originária, assente num sistema de "regras" ("rule-based governance").

A partir do Pacto de Estabilidade e Crescimento, estipulado em 1997, a fiscalização articula-se em duas fases: a "preventiva" (Council Regulation (EC) N. 1466/97) e a "dissuasiva" (Council Regulation (EC) N. 1467/97). A insuficiência da regulamentação manifestou-se muito anteriormente à crise de 2010. A prova disso são as modificações concordadas no Conselho Europeu de março de $2005,{ }^{[7]} \mathrm{com}$ as quais os procedimentos de défice excessivo eram complementados com termos certos para satisfazer o critério do défice e com a definição do seu instrumento príncipe, ou seja o "objetivo orçamental de médio prazo", que determina o percurso de ajustamento das contas públicas. Esta primeira reforma visava corrigir uma falha ulterior do originário Pacto de Estabilidade: a sua falta de flexibilidade em relação ao ciclo económico e, portanto, os seus efeitos pró-cíclicos. As metas orçamentais eram moduladas consoante o ciclo económico e em relação ao nível da dívida pública, à duração do período de baixo crescimento, e tendo em conta os custos de medidas estruturais aptas a incrementar o crescimento.

As sucessivas alterações, consolidadas nas medidas dos assim chamados "Six-" (Regulations N. 1177/2011, N. 1173/2011, N. 1174/2011, N. 1175/2011, N. 1176/2011, Directive N. 2011/85/UE) e “Two-Pack" (Regulations N. 472/2013 e N. 473/2013) e no Tratado de Estabilidade, Coordenação, e Governança (TSCG) de 2 de março 2012 (informalmente conhecido como "Fiscal Compact" e estipulado como tratado internacional) ${ }^{[8]}$, instituem um reforço ulterior da fase preventiva (que se concretiza no "Semestre Europeu", ou seja, numa fase de fiscalização prévia dos orçamentos nacionais e dos projetos de reformas estruturais por parte da Comissão) e da fase dissuasiva (que se concretiza num conjunto de mecanismos supostamente automáticos de reajustamento dos orçamentos nacionais em caso de derrapagem). Para além de prever que o princípio do equilíbrio orçamental seja integrado na legislação nacional dos estados membros, preferencialmente através do direito constitucional, o Tratado altera as condições com as quais o Conselho adota as eventuais penalizações propostas pela Comissão em caso de incumprimento, quantificadas agora de forma certeira e que têm de ser rejeitadas por uma maioria qualificada.

7. Council of the European Union. (2005). European Council Brussels, 22 and 23 March 2005. Presidency Conclusions. (7619/1/05 REV 1). Brussels, Belgium: Council of the European Union, <http://www.consilium.europa.eu/ueDocs/cms_Data/docs/pressData/en/ec/84335.pdf $>$ [acedido a 30.3.2018].

8. Veja-se Treaty on Stability, Coordination, and Governance, <http://european-council.europa.eu/media/ 639235/st00tscg26_en12.pdf> [acedido 30.3.2018]. 
Manifesta-se aqui uma característica muito controversa da arquitetura da zona euro: a sua constituição "jurídica” e não "política”, ou seja, o facto de o sistema ser assente num mecanismo de controlo de natureza "quase-jurídica", e não no princípio da responsabilidade política da tomada de decisões. A diferença consiste no facto das regras serem implementadas com base numa avaliação "técnica" de valores orçamentais e de forma a não serem (idealmente) sujeitas à discrição duma autoridade, mas, pelo contrário, "calculáveis" nos seus efeitos e na sua interpretação. Uma tal arquitetura é assente no princípio da divisão entre uma fase "política", na qual os estados membros negoceiam um tratado do qual darão conta aos seus eleitores nacionais, e uma fase "administrativa" da qual a Comissão é encarregue e cuja legitimidade é assente na implementação transparente e formalmente correta dos procedimentos estipulados. Um tal sistema visa minimizar o especto negocial da implementação. A expetativa que o justifica é que os estados membros, na altura de negociar o acordo, possam avaliar as consequências da sua implementação. Desta forma, a transferência de soberania traduz-se num exercício de cálculo "certeiro" do qual os responsáveis políticos nacionais podem razoavelmente dar conta aos cidadãos no momento eleitoral, ou perante os seus parlamentos. Tal é, na sua raiz, o raciocínio com o qual o Tribunal Constitucional alemão aprovou as instituições e as medidas de urgência que foram utilizadas na fase aguda da crise da dívida para atuar os resgates (Thompson, 2015).

As "regras" têm também outra função fundamental no concerto europeu: a de limitar os conflitos entre os países membros. Sendo estabelecidas por unanimidade, as regras atribuem às autoridades políticas de cada membro o poder de vedar decisões que considera excessivamente contrárias aos seus interesses. Sendo a fase "política" assim limitada, a implementação das regras não produz, supostamente, conflitos ulteriores, o que seria o caso se a tomada de decisões fosse entregue a órgãos estruturados em minorias e maiorias políticas. Por isso, um tal modelo de governança é considerado adequado a uma União que mantém as características de uma "entidade reguladora”. Dúvidas surgem, porém, se da União merecer ainda uma tal caracterização tendo em conta a abrangência das políticas nacionais sobre as quais as instituições europeias têm influência no contexto da UEM (Majone, 1998).

Outra razão para estruturar a arquitetura da zona euro num sistema de regras é, mais uma vez, o problema da coordenação entre atores independentes e soberanos, ou seja, a eliminação do "parasitismo". Na zona euro, os estados membros são encarregues de gerir de forma autónoma e independente um conjunto de bens comuns, que se podem resumir na estabilidade monetária. No mesmo tempo, o interesse de cada um pode divergir deste objetivo. Pelo contrário, em virtude da responsabilidade política nacional do representante de cada estado, cada membro é sujeito à tentação de externalizar os custos da sua própria tarefa. Um sistema de regras de implementação a mais "automática" possível (ou seja, independente da autonomia de juízo político de cada um dos atores), é uma garantia de cumprimento para com todos os outros. Um tal sistema situa a responsabilidade política ao nível nacional, não visando na UEM a constituição de uma "polity" ou um espaço verdadeiramente comum, e neste sentido "solidário", de intervenção política, mas sim um acordo, uma convergência 
de interesses entre estados soberanos. Na mesma lógica, o que for ao encontro dos interesses dos parceiros é interpretado como "solidariedade", e não como uma responsabilidade comum num sistema de interdependências económicas e institucionais ${ }^{[9]}$.

Assim, a UEM não constitui um sistema de cooperação com base num interesse comum, mas sim uma convergência de interesses particulares à volta de um instrumento, a moeda, cuja funcionalidade é garantida por um sistema de controlo recíproco gerido por regras. O aspeto problemático de uma tal construção não consiste tanto na convergência de interesses particulares ou nacionais, o que, pelo contrário, representa a motivação que fundamenta a adesão à moeda comum, quanto na facilidade com a qual podem intervir desequilíbrios macroeconómicos que reduzem os efeitos benéficos da União monetária e põem em risco a sua sustentabilidade um risco que só uma tomada coletiva de responsabilidade para a economia da zona euro no seu conjunto, nomeadamente através de uma mais abrangente coordenação macroeconómica, podia desconjurar.

Pelo contrário, a falta de coordenação macroeconómica acompanha-se a uma competição entre economias nacionais marcada pela tentativa de ganhar uma competitividade que se mede em avanços na balança corrente - uma prática quase autorizada pelas regras, que os fiscalizam de forma diferente e menor em comparação aos défices orçamentais, e que até agora nunca deram lugar à um procedimento de infração, não obstante as reiteradas derrapagens de alguns estados membros. Desta forma, os desequilíbrios macroeconómicos fazem para que as relações políticas entre os estados sejam marcadas pela sua posição de credores ou devedores, ou pelos diferentes valores de mercado dos próprios certificados de crédito públicos (Habermas, 2015). Tais posições foram determinantes na definição das condições dos resgates, especialmente no caso grego, ou das próprias reformas da governança económica (Thompson, 2015, p. 867).

Em conclusão, a arquitetura da UEM resulta de um entendimento da finalidade da moeda comum que determina um conjunto de fatores políticos e económicos problemáticos para a sua sustentabilidade: o facto de não ter em conta todas as externalidades das políticas nacionais, em primeiro lugar, e os limites de um quadro normativo assente em "regras" inspiradas a um mecanismo jurídico, em segundo lugar. De formas e de perspetivas diferentes, as críticas às políticas de austeridade chamam a atenção para esta dupla e problemática raiz da arquitetura da zona euro.

\section{A necessidade da cooperação para a estabilidade da UEM}

Não obstante seja focada sobre a minimização das externalidades do comportamento fiscal dos estados membros, a arquitetura da zona euro nada faz para limitar outros tipos de externalidades: os que afeitam a convergência macroeconómica e que são o produto de escolhas de política laboral, salarial, e de despesa pública e privada. De

9. Veja-se, a este propósito, o documento que resulta das recentes negociações para uma coligação entre CDU-CSU e SPD em Berlim: Ergebnisse der Sondierungsgesprache von CDU, CSU und SPD-Finale Fassung, Berlin, January 12, 2018. 
facto, as reformas da zona euro não tocam na repartição dos custos de tal convergência, nem preveem mecanismos para a incentivar. São, em particular, os custos sociais da convergência a serem entregues à política nacional, enquanto a coordenação dos ciclos económicos é excluída de todo do sistema de regras da arquitetura da UEM.

$\mathrm{Na}$ distinção da teoria dominante das áreas monetárias — a teoria das áreas monetárias ótimas, de Mundell (1961) —, num regime de autonomia monetária, as flutuações da taxa de câmbio refletem as diferentes produtividades das economias nacionais, que são um produto de escolhas de política fiscal, laboral, de investimentos, etc. A taxa de câmbio assinala, portanto, o estado da competitividade dos atores nacionais no mercado internacional e adapta, idealmente, o valor da moeda a tais relações de competitividade. Pelo contrário, num regime de moeda única, a adaptação cabe aos preços e aos salários, que determinam os custos de produção e a vantagem ou desvantagem competitiva dos atores económicos. Em caso de perda de competitividade, os mecanismos de adaptação consistem, portanto, numa diminuição de preços e salários, na realocação geográfica ou até na migração de trabalhadores, e na intervenção da fiscalidade pública (por exemplo para investimentos ou reformas que incrementem a competitividade).

A pesquisa científica ainda não esclareceu completamente a importância relativa destes fatores (Blanchard, 1992). Contudo, é opinião universal que estes mecanismos ou políticas de adaptação às condições de mercado intervêm com menor solicitude do que as alterações da taxa de câmbio. No contexto europeu há, para além disso, barreiras (linguísticas ou de acesso às informações, no caso das oportunidades de trabalho, e de regras orçamentais, no caso da fiscalidade pública) que limitam a capacidade de adaptação.

A "consensus view" ${ }^{[10]}$ sobre as origens e as causas da crise da dívida soberana vê nestas especificas condições do contexto europeu e na uniformidade da taxa de juros do Banco central o motor que, nos anos 2000, levou a um fluxos de capitais dos países que, pela sua própria dinâmica económica conjuntural de baixo crescimento, teriam precisado de taxas de juros inferiores, para os países que, pelas suas mais elevadas taxas de crescimento, teriam precisado de uma taxa de juros maior.

Os fluxos de capitais não são, note-se bem, um problema em si. São, pelo contrário, uma consequência necessária dos complementares interesses nacionais que justificam a existência da UEM. Os países que desejavam aproximar o próprio bem-estar ao dos parceiros mais competitivos podiam ter mais fácil acesso ao crédito sem ter de descontar o risco relacionado com a própria instabilidade ou fraqueza monetária.

10. Uma controvérsia ainda existente no debate científico diz respeito ao papel que tiveram os desequilíbrios na balança comercial. Em particular, a dúvida surge em relação à questão se a crise tenha que ser interpretada em analogia às crises de competitividade, e sucessivamente de liquidez, própria de países com taxa de câmbio fixa para com outras moedas (o que justificaria a austeridade como estratégia de recuperação de competitividade internacional), ou como crise de liquidez devida puramente a desequilíbrios no mercado dos capitais. Vejam-se Collignon, S. (2012). Macroeconomic imbalances and competitiveness in the euro area. Transfer, 19(1) 67-8, e Baldwin, R. \& Giavazzi, F. (2015). The Eurozone Crisis: A Consensus View of the Causes and a Few Possible Solutions. London, UK: CEPR Press. Contudo, as consequências das duas leituras da crise para a arquitetura da zona euro não necessariamente diferem. 
Os países mais competitivos podiam, do seu lado, ter maiores oportunidades num mercado com reduzidos riscos de câmbio e com menores custos de transação ${ }^{[11]}$.

As motivações que estiveram na base do interesse da República Portuguesa à adesão ao euro foram recentemente resumidas pelo então Primeiro-ministro, Cavaco Silva, numa apresentação na Sociedade de Geografia (Lisboa, 18 de janeiro, 2018), e são comuns a um conjunto de países: o acesso facilitado a um mercado maior em virtude de taxas de juros mais estáveis (e inferiores ao padrão até então conhecido) e da anulação do risco de câmbio. Daí um crescimento potencial correspondentemente maior. De facto, estes efeitos esperavam-se mais relevantes para os países cujas moedas nacionais eram mais sujeitas a flutuações de mercado. Por isso, a dinâmica do fluxo de capitais não é surpreendente em $\mathrm{si}^{[12]}$. Problemática é a ausência de instrumentos atos a garantir a governação desta dinâmica.

Uma tal dinâmica dos fluxos dos capitais resultou, ao longo da década, em desequilíbrios na balança dos pagamentos, em bolhas (especialmente imobiliárias), por um lado, e num crescimento da competitividade inferior ao necessário, por outro (Feldstein, 2010). A diferença nas respetivas taxas de inflação alterou as relações de competitividade para além da contingência do ciclo económico, fazendo que os preços não seguissem as efetivas capacidades competitivas dos atores nacionais ${ }^{[13]}$. Esta dinâmica, em si devida às condições da arquitetura monetária da zona euro e aos incentivos aos investidores que se vieram a criar, juntou-se às escolhas de política salarial e orçamental dos países membros, e especialmente à escolha que um conjunto de países fez (especialmente a Alemanha e a área económico-produtiva europeia que é mais integrada com a economia alemã) de tentar ultrapassar a fase de baixo crescimento praticando uma moderação salarial que fizesse que a economia nacional no seu conjunto se tornasse mais competitiva no mercado internacional. Reflete-se aqui, em geral, uma interpretação da globalização económica que na cultura política e económica alemã começou a enraizar-se no final da década de 1980 e que vê no reforço da capacidade de exportação através da alavanca da centralização das relações laborais o meio para a sobrevivência do modelo social alemão ${ }^{[14]}$.

11. Veja-se Ferreira-Lopes, A. (2010). In or out? The welfare costs of EMU membership. Economic Modelling, 27(2), 585-594, para uma análise diferenciada das vantagens na adesão à moeda comum.

12. Veja-se Blanchard, O. (2007). Current Account Deficits in Rich Countries (NBER Working Papers, 12925).

13. European Central Bank, Monetary policy and inflation differentials in a heterogeneous currency area, <www.ecb.int/pub/pdf/other/pp61_77_mb200505en.pdf> [acedido a 10 de dezembro 2017].

14. Sobre a vantagem competitiva de relações sindicais centralizadas veja-se Höpner, M. (2013). Die Verschiedenheit der europäischen Lohnregime und ihr Beitrag zur Eurokrise. MPIfG Discussion Paper, 13 (5), e Rodl, F. \& Callsen, R. (2014). The Struggle for Union Rights Under the Euro and the Dialects of Social Integration. In Glinski, C. \& Joerges, C, The European Crisis and the Transformation of European Governance (pp. 101-121). Oxford and Portland, USA: Hart. 


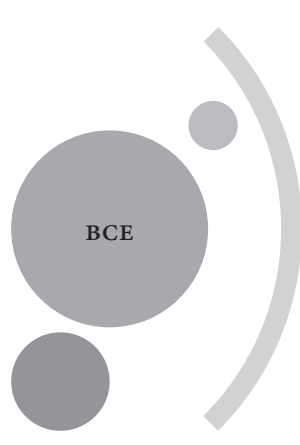

TAXAS DE JUROS PRÓ-CÍCLICAS

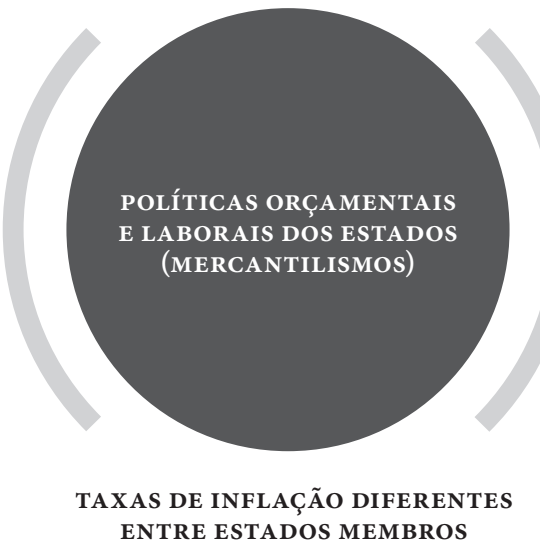

ENTRE ESTADOS MEMBROS

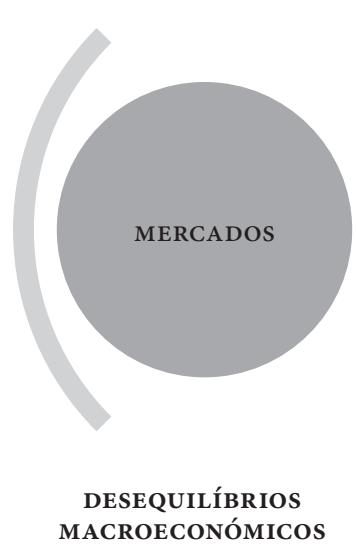

Esquema 1. Mecanismos estruturais na base da crise do euro

As condições criadas por estes fatores determinaram uma estrutura de incentivos que levou os investidores a desinvestir de forma repentina nos países cujas bolhas rebentaram em consequência da crise dos créditos subprime nos Estados Unidos em 2007-2008. O fenómeno de "sudden stop" foi facilitado pela rigidez das regras europeias, pela evidente falta de uma resposta coordenada e positiva dos países europeus, e finalmente pela escolha do Banco Central Europeu de praticar uma política monetária restritiva no momento em que a crise se manifestou ${ }^{[15]}$. Mais uma vez, as escolhas políticas dos membros do concerto europeu foram ditadas pela posição e os interesses dos próprios investidores nacionais no mercado internacional, por um lado, e pelas diferentes estratégias de longo prazo de adaptação ao mercado internacional (estratégias fortemente individuais e alheias tanto à cooperação quanto à partilha de riscos comuns), por outro.

15. Veja-se uma acurada e documentada reconstrução desta fase da crise, aplicada a Portugal, Abreu, A., Alves, P., Gusmão, J., Mamede, R., Mendes, H., Rodrigues, J., ... Teles, N. (2013). A Crise, a Troika e as Alternativas Urgentes. Lisboa, Portugal: Tinta da China. 


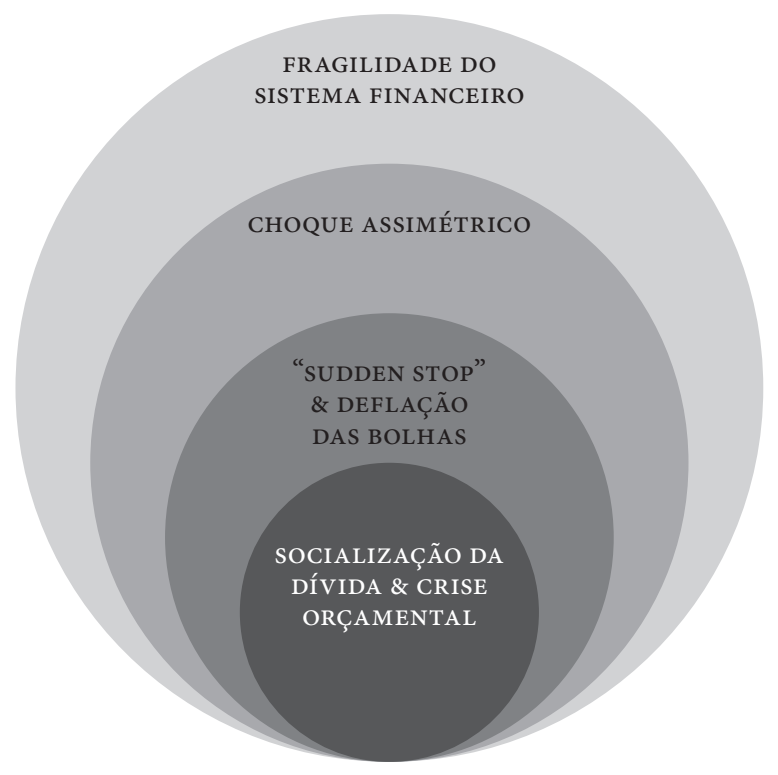

Esquema 2. Causas contingentes da crise da dívida soberana

Nas causas profundas da crise manifesta-se, portanto, a natureza atual da arquitetura da UEM: a zona euro é um conjunto de estados que entretêm relações de concorrência económica - uma concorrência gerida através do controlo dos custos salariais e fiscais. Num tal contexto, torna-se impossível a gestão cooperativa dos "bens comuns" (Busch, 2009; Hacker, 2011). É por isso que a atual arquitetura da zona euro merece ser definida "mercantilista".

Contudo, enquanto cada país é chamado a cuidar de si e dos seus próprios destinos económicos, a convergência ou a divergência das economias nacionais dependerão, pelo contrário, de um conjunto de escolhas nacionais independentes de um ponto de vista político, mas interdependentes de um ponto de vista económico.

$\mathrm{Na}$ arquitetura original da moeda única, este tipo de externalidades, que se manifestam através de avanços consistentes e duradouros na balança corrente, era em grande parte "autorizado", na medida em que não havia, e não há de facto atualmente, mecanismos para o limitar ou sancionar. Por conseguinte, cada ganho de competitividade por parte de uma economia nacional acontecia, de uma certa forma, à custa das outras. É assim que as relações entre as economias nacionais são direcionadas no sentido de uma competição, e não de uma cooperação, sendo a convergência uma tarefa exclusiva dos "atrasados".

Acrescenta a este tipo de desequilíbrio a política monetária do Banco Central Europeu e a sua determinação da uma taxa de juros única para a zona euro no seu conjunto. Da fusão destas duas falhas: de política monetária e de falta de coordenação das decisões orçamentais, resulta a crise da dívida soberana, nas reconstruções que espelham a visão mais frequente e bem fundamentada dos economistas. 


\section{Hipóteses para uma arquitetura cooperativa da UEM}

Há muitas lições para aprender da crise da dívida soberana. A primeira é que a convergência macroeconómica muito dificilmente será o produto do mercado comum e dos esforços individual dos países membros. Nos documentos oficiais e na estrutura da governança da União há, de facto, um implícito reconhecimento da insuficiência do mercado comum para a convergência das economias dos estados membros. Este reconhecimento concretiza-se na promoção de um "diálogo social", na existência de uma Carta Social ou no Acordo de Maastricht sobre a Política Social.

Contudo, estas instituições são de caráter voluntário, e não incidem sobre as políticas nacionais ou os acordos sindicais. Mas a consciência de quão abrangente é o conjunto de medidas a tomar e reformas a implementar para que o mercado e a moeda comuns sejam sustentáveis em termos políticos e económicos é bem presente nos documentos da Comissão, e emerge indiretamente também nos tratados entre os países membros. Por exemplo, o Pacto EuroPlus de 2011, ou seja, ainda na fase aguda da crise da dívida e em plena promoção das políticas de austeridade, indica um conjunto de políticas que é necessário empreender para a sustentabilidade da UEM. Tais políticas incluem a contratação salarial (e sugerem a adesão a um modelo centralizado de contratações), a redução dos impostos que pesam sobre o custo do trabalho, os sistemas de pensões, a saúde pública e o estado social no seu conjunto.

Tais reformas, que já são habitualmente discutidas no âmbito do Semestre Europeu, levantam uma questão ulterior, relativa à eficácia com a qual um sistema de regras pode gerir um conjunto tão abrangente e politicamente sensível de reformas e políticas nacionais.

$\mathrm{Na}$ medida em que abordam a lógica da arquitetura da UEM, os documentos da Comissão levantam questões ainda mais relevantes, especialmente no que diz respeito ao nível de cooperação macroeconómica e fiscal que a sustentabilidade da zona euro requer. Através de numerosos documentos produzidos a partir de 2015, a Comissão tem vindo a promover um conjunto de reformas à volta das quais se desenvolvem o debate e os conflitos correntes. Em particular, a Comissão parece ter reconhecido que uma moeda comum gera riscos comuns (a partir do facto de políticas fiscais mal coordenadas poderem ter efeitos agregados pró-cíclicos), e tem, portanto, de incluir adequados mecanismos de absorção de tais riscos. Isso requer, por sua vez, que a lógica da pura manutenção do valor da moeda num contexto de competição económica entre economias nacionais seja abandonada em favor de uma lógica de corresponsabilidade pela estabilidade macroeconómica, o que inclui a competitividade dos parceiros. A Comissão reconhece que os países têm de ter a possibilidade de recuperar através da legislação comunitária aqueles instrumentos de adaptação ao mercado internacional que têm vindo a perder com a adesão à moeda comum.

As propostas da Comissão visam balançar as necessidades de prevenir o "parasitismo" e de promover medidas que favoreçam a competitividade em cada estado membro, com mecanismos de partilha de riscos que tenham em conta os vários tipos de externalidades que a participação ao mercado e à moeda comuns podem gerar. $\mathrm{O}$ acesso a tais mecanismos dependerá do cumprimento das regras. Secundariamente, as propostas da Comissão propõem de ir para além de um sistema de governança 
económica assente em regras no sentido duma mais abrangente cedência de soberania que inclua adequados mecanismos de legitimação política. Estas propostas são articuladas em documentos redigidos a partir do assim chamado "Relatório dos cinco presidentes" ${ }^{[16]}$.

Reconhecendo a complexidade da tarefa de garantir a competitividade e a convergência económica num mercado que apresenta um alto nível de integração, como é o mercado europeu, as propostas da Comissão visam em primeiro lugar estender o âmbito das políticas nacionais abrangidas pela coordenação macroeconómica. Trata-se, neste sentido, de dar corpo ao programa do Pacto EuroPlus, que é um tratado internacional não vinculativo estipulado no contexto do Método Aberto de Coordenação. Assim, a Comissão reconhece a importância das negociações salariais na determinação das condições de competitividade, e promove a centralização das relações sindicais (como no modelo alemão). As reformas estruturais deveriam também subjazer a padrões europeus inseridos na legislação comunitária que incluem os mercados laborais, a administração pública, a fiscalidade das empresas, etc. Os acessos aos mecanismos financeiros de apoio em caso de crise dependeriam do cumprimento de tais padrões ou do progresso das reformas correspondentes.

Para além dos evidentes problemas de legitimação política, uma tão abrangente partilha de soberania ao nível comunitário levanta a questão da efetiva capacidade das instituições comunitárias de levar a cabo a tarefa da coordenação, tendo em conta as atuais dificuldades em fazer para que as indicações do Semestre Europeu sejam cumpridas (para além das orçamentais, que, de resto, são também objeto de intensas negociações) $)^{[17]}$.

Mais interessantes, e com mais perspetivas, são as propostas relativas aos mecanismos de partilha de riscos. O primeiro é a União bancária, que a Comissão convida a completar em 2018, e que já começou a ser implementada através da Diretiva 2014/49/EU, relativa aos sistemas de garantia de depósitos (abril 2014), da Diretiva 2014/59/EU, que estabelece um enquadramento para a recuperação e a resolução de instituições de crédito (maio 2014), do Regulamento UE N. 575/2013 de 26 de junho de 2013, relativo aos requisitos prudenciais para as instituições de crédito, e da Diretiva 2013/36/UE, relativa ao acesso à atividade das instituições de crédito (junho 2013). Por falta de confiança na banca dos parceiros, e pela desconfiança que acompanha a perspetiva de partilhar riscos de outrem, em geral (Nars \& Nienaber, 2018), é, porém, ainda ausente a parte relativa à partilha de riscos, ou seja o seguro comum sobre as contas bancarias e o assim chamado "back stop" do fundo de resgate das resoluções bancarias. A União bancária deveria ser complementada por uma União dos mercados financeiros.

16. Jean-Claude Juncker (June 2015), Completing Europe's Economic and Monetary Union. A Report by JeanClaude Juncker in close cooperation with Donald Tusk, Jeroem Dijsselbloem, Mario Draghi, and Martin Schulz (4-5), Brussels.

17. Darvas, Z. \& Leandro, A. (2015, November 18). Naughty students or the wrong school: why is the European Semester proving ineffective? Bruegel, <http://bruegel.org/2015/11/naughty-students-or-thewrong-school-why-is-the-european-semester-proving-ineffective/> [acedido a 10.12.2017]. 
Estas reformas visam criar um mercado continental dos capitais dentro do qual os atores económicos não tenham de descontar o risco-país, e que possa, portanto, garantir igualdade de acesso aos recursos financeiros. Um objetivo ulterior consiste em diferenciar as fontes de financiamento às empresas de forma, diferenciar, por conseguinte, os riscos, e reduzir o papel da banca. A União bancária visa também responsabilizar os atores pelos riscos associados às suas atividades independentemente do país de atuação, contribuindo desta forma à criação de uma consciência e de uma prática transnacional de partilha de riscos.

Enquanto a União bancária parece ser uma reforma bem avançada, outras reformas são objeto de controvérsia. Destaca-se uma, em particular, que resultaria numa duradoura modificação da estrutura atual (disfuncional, como acima evidenciado) de incentivos políticos e económicos. Esta reforma consistiria numa coordenação das políticas orçamentais dos países membros. Esta é a reforma mais importante.

Uma tal reforma, já acenada no relatório do Presidente da Comissão Juncker e sucessivamente definida num documento de 2016 (Juncker et al., 2016), enfatiza a necessidade da zona euro alcançar uma posição orçamental agregada que acompanhe a política monetária no esforço de estimular o crescimento económico, que permanece abaixo do potencial desde a crise da dívida soberana, num contexto em que permanecem riscos ligados à dívida e ao défice orçamental de alguns países. Uma posição fiscal agregada que não seja restritiva nem neutral, mas sim moderadamente expansiva, facilitaria a tarefa de fazer para que inflação suba para o objetivo de $2 \%$ (o que aliviaria a posição dos países com problemas de endividamento). Isso, por sua vez, seria um pressuposto para uma normalização das taxas de juros, o que seria bem-vindo por parte dos países cuja posição orçamental não necessita de intervenções urgentes ou consistentes, mas que têm, por sua parte, um problema de gestão de poupanças: ou mesmo vale para todos os países cuja posição da banca desperta preocupações.

Os efeitos de uma coordenação das políticas orçamentais iriam para além da contingência do ciclo económico, e seriam positivos para a redução dos desequilíbrios macroeconómicos através das mudanças na posição relativa dos países com défices e dos países com excedentes comerciais, permitindo aos países que precisam de cuidar prioritariamente da consolidação orçamental de reduzir as despesas sem que isso seja pago em termos de menor crescimento, e permitindo, ao mesmo tempo, aos países com maior margem orçamental de gozar os resultados das suas "virtudes fiscais". Embora seja formulada como se fosse uma medida contingente e finalizada à gestão da atual fase de insuficiente recuperação económica, a importância da proposta da Comissão é estrutural.

Infelizmente, o atual quadro normativo não só não permite praticar uma tal coordenação por falta de instrumentos, mas exige também uma ação contrária no caso (frequente) em que as recomendações orçamentais dirigidas aos países membros se limitem a aplicar as regras sem ter em conta a posição agregada da zona euro ${ }^{[18]}$. Da mesma forma, as regras orçamentais não permitem coordenar e repartir os esforços

18. Comissão Europeia (2016), Towards a positive fiscal stance, 2. 
de crescimento entre os países membros, mesmo que uma tal coordenação não implique redistribuição de recursos entre os países e evite, portanto, os relativos conflitos. Uma ulterior reforma anunciada para 2018, ou seja a inclusão do Tratado de Estabilidade, Coordenação, e Governança, prevista no seu dispositivo legal, acrescenta os impedimentos a uma tal coordenação ${ }^{[19]}$. A inclusão do núcleo normativo do tratado na legislação comunitária, e especialmente do Artigo 3, que prescreve mecanismos "automáticos" de acerto de contas para a redução constante e programada do défice, não implica alterações fatuais ao estado atual da legislação, mas constitui uma prova ulterior da dificuldade em alterar a lógica subjacente à arquitetura atual da UEM. No documento apresentado ao Conselho, ao qual compete a decisão, a Comissão reconhece que, por causa das contingências do ciclo económico, o automatismo nunca foi até agora verdadeiramente implementado ${ }^{[20]}$. A sua inserção na legislação poderia ser uma oportunidade para consolidar a prática prevista no Tratado.

Contrariamente ao que é previsto por estes dispositivos legais, estipulados na fase aguda da crise, quando a preocupação era reforçar a responsabilidade orçamental individual dos países, a decisão de reforçar os instrumentos de coordenação fiscal responderia às questões políticas levantadas pela arquitetura da zona euro e traçadas anteriormente.

Em primeiro lugar, a coordenação macroeconómica consentiria aos países membros de não ter de enfrentar sozinhos a tarefa de se adaptar às condições do mercado, mas sim de estabelecer relações de corresponsabilidade pelas externalidades que as políticas de competição poderiam gerar. A coordenação daria, aliás, um contributo considerável à redução de uma tal competição.

Em segundo lugar, uma tal coordenação consentiria de reduzir os riscos de conflito político entre os países na medida em que não implica redistribuição de recursos. Contemporaneamente, os (reduzidos) efeitos da competição económica não se traduziriam em desigualdade política, em virtude do quadro de cooperação que se criaria no Conselho. A coordenação macroeconómica reduziria também a conflitualidade que se cria entre os países e a Comissão no momento da fiscalização prévia dos orçamentos dos estados, uma conflitualidade que evidenciou o tamanho da margem de discrição da Comissão na aplicação das regras orçamentais (Maatsch, 2017).

\section{Conclusão:}

\section{o estado atual do debate sobre as reformas e os obstáculos à cooperação}

A coordenação orçamental precisa de um acordo de princípio entre os estados membros, um acordo que inclua uma mudança de atitude perante os riscos comuns implícitos na UEM. Em particular, os estados membros deveriam aceitar uma redistribuição do esforço para a convergência das economias nacionais. Uma tal redistribuição, que não implicaria uma transferência de recursos, mas sim o abandono da política

19. Comissão Europeia (2017, December 6). Proposal for a Council Directive laying down provisions for strengthening fiscal responsibility and the medium-term budgetary orientation in the Member States. (COM 2017, 824 final).

20. Comissão Europeia (2017, December 6). Proposal for a Council Directive, 2. 
de reforço mercantilista da competitividade da própria economia nacional, torna-se mais provável pelo facto de trazer consigo vantagens para todos os participantes, constituindo assim uma situação de “win-win”. Uma coordenação das políticas orçamentais daria aos países com menor margem de manobra fiscal uma concreta hipótese de redução dos défices, e contribuiria, portanto, à estabilidade da moeda comum. A coordenação daria, no mesmo tempo, aos países com situações orçamentais melhores uma oportunidade para aproveitar os seus excedentes em termos de bem-estar maior.

Contudo, não parece ser este o caminho que os membros da UEM são dispostos a tomar. A Comissão (que tem o cuidado de formular propostas com base nas preferências dos países membros) tem de facto selecionado o mecanismo de estabilização fiscal que menos codecisão exige por parte dos parceiros europeus, e de tentar alcançar através deste, ou seja indiretamente, a coordenação orçamental ${ }^{[21]}$. $\mathrm{O}$ instrumento previsto consiste em fundos comunitários para sustentar os investimentos em casos de quebra no crescimento, especialmente se devida a um "choque assimétrico", ou seja, a fatores externos que incidem de forma diferente sobre as economias nacionais dos países membros. A sugestão da Comissão inclui, de facto, um mecanismo de mútuo seguro, mas um tal mecanismo, que marcaria o pleno reconhecimento das interdependências económicas, financeiras e fiscais, teria uma base meramente voluntária ${ }^{[22]}$. Tendo como base financeira o orçamento europeu, os fundos que a Comissão propõe apresentam a vantagem de constituir um esforço orçamental previsível por parte dos estados membros. Tais fundos não exigiriam alterações profundas nos mecanismos de funcionamento da União, e seriam sujeitos a uma periódica renegociação, nomeadamente na altura de refinanciar o orçamento comunitário (propostas, também presentes, de equipar a União com recursos próprios não alteram radicalmente estas características do mecanismo). O maior limite desta proposta é de não oferecer um método contínuo e constante de coordenação macroeconómica e, portanto, de prevenção de riscos, mas sim um instrumento que produziria os seus efeitos só em caso de crise de liquidez orçamental ou bancária.

Por isso, a proposta atual é insuficiente a desencadear os mecanismos virtuosos de coordenação e partilha de responsabilidade que seriam necessários para a estabilização duradoura da zona euro, e que só uma reestruturação da arquitetura da UEM no sentido de uma maior cooperação (e do abandono do mercantilismo) é capaz de alcançar.

21. Comissão Europeia (2017, December 6). New Budgetary Instruments for a Stable Euro Area within the Union Framework. (COM 2017, 822 final: 7-13).

22. Comissão Europeia (2017, December 6). New Budgetary Instruments, 15. 


\section{Referências}

Abreu, A., Alves, P., Gusmão, J., Mamede, R., Mendes, H., Rodrigues, J., ... Teles, N. (2013). A Crise, a Troika e as Alternativas Urgentes. Lisboa, Portugal: Tinta da China.

Andor, L. (2018). Austerity: From Outrage to Progressive Alternatives. Social Europe. Retirado de <https://www.socialeurope.eu/austerity-outrage-progressive-alternatives $>$ [acedido a 15.02.2018].

Baimbridge, M., Burkitt, B \& Whymann, B. (2012). The Eurozone as a flawed currency area. The Political Quarterly, 83(1), 96-107.

Baldwin, R. \& Giavazzi, F. (2015). The Eurozone Crisis: A Consensus View of the Causes and a Few Possible Solutions. London, UK: CEPR Press.

Blanchard, O. (1992). Regional Evolutions. Brookings Papers on Economic Activity, 1, 1-75.

Blanchard, O. (2007). Current Account Deficits in Rich Countries (NBER Working Papers, 12925). Cambridge, EUA: National Bureau of Economic Research.

Busch, K. (2009). Weltwirtschaftskrise und Wohlfahrtsstaat. Berlim: Friedrich Ebert Stiftung.

CDU, CSU \& SPD (2018). Ergebnisse der Sondierungsgesprache von CDU, CSU und SPD Finale Fassung. Berlim, Alemanha. [Acedido a 10.02.2018]

Collignon, S. (2012). Macroeconomic imbalances and competitiveness in the euro area. Transfer, 19 (No. 1) 63-87.

Comissão Europeia (2016, November 16). Towards a Positive Fiscal Stance for the Euro Area (COM (2016) 727 final). Brussels, Belgium: European Commission.

Comissão Europeia (2017, December 6). New Budgetary Instruments for a Stable Euro Area within the Union Framework. (COM 2017, 822 final). Brussels, Belgium: European Commission.

Comissão Europeia (2017, December 6). Proposal for a Council Directive laying down provisions for strengthening fiscal responsibility and the medium-term budgetary orientation in the Member States. (COM 2017, 824 final). Brussels, Belgium: European Commission.

Council of the European Union (2005). European Council Brussels, 22 and 23 March 2005. Presidency Conclusions. (7619/1/05 REV 1). Brussels, Belgium: Council of the European Union. Retirado de <http://www.consilium.europa.eu/ueDocs/cms_Data/docs/ pressData/en/ec/84335.pdf $>$ [acedido a 30.03.2018].

Darvas, Z. \& Leandro, A. (2015, November 18). Naughty students or the wrong school: why is the European Semester proving ineffective? Bruegel. Retirado de <http://bruegel. org/2015/11/naughty-students-or-the-wrong-school-why-is-the-european-semester-proving-ineffective/> [acedido a 10.12.2017].

Diretiva 2013/36/UE do Parlamento Europeu e do Conselho de 26 de junho de 2013, relativa ao acesso à atividade das instituições de crédito e à supervisão prudencial das instituições de crédito e empresas de investimento, que altera a Diretiva 2002/87/CE e revoga as Diretivas 2006/48/CE e 2006/49/CE. Jornal Oficial da União Europeia, L 176/338.

Diretiva 2014/49/UE do Parlamento Europeu e do Conselho de 16 de abril de 2014, relativa aos sistemas de garantia de depósitos (2001). Jornal Oficial da União Europeia, L $173 / 149$. 
Diretiva 2014/59/UE do Parlamento Europeu e do Conselho de 15 de maio de 2014, que estabelece um enquadramento para a recuperação e a resolução de instituições de crédito e de empresas de investimento e que altera a Diretiva 82/891/CEE do Conselho, e as Diretivas 2001/24/CE, 2002/47/CE, 2004/25/CE, 2005/56/CE, 2007/36/CE, 2011/35/CE, 2012/30/UE e 2013/36/UE e os Regulamentos (UE) n. 1093/2010 e (UE) n. 648/2012 do Parlamento Europeu e do Conselho. Jornal Oficial da União Europeia, L 173/190.

European Central Bank (2005). Monetary policy and inflation differentials in a heterogeneous currency area. Monthly Bulletin, May. Retirado de <www.ecb.int/pub/pdf/ other/pp61_77_mb200505en.pdf> [acedido a 10.12.2017].

European Union (1992). Treaty on European Union, Article 109j (No.C191). Maastricht, Netherlands: Official Journal of the European Communities.

Feldstein, M. (1992). The Case Against EMU. The Economist, 13, 23-26.

Feldstein, M. (2010). The Euro's Fundamental Flaws. The International Economy, 24(2), 12.

Ferreira-Lopes, A. (2010). In or out? The welfare costs of EMU membership. Economic Modelling, 27 (2), 585-594.

Godley, W. (1997). The Hole in the Treaty. In J. Shahin \& M. Wintle, The Idea of a United Europe. Political, Economic and Cultural Integration since the Fall of the Berlin Wall (pp 173 - 177). Houndsmill and London: Macmillan.

Habermas, J. (2015, June 22). Warum Merkels Griechenland-Politik ein Fehler ist Suddeutsche Zeitung. Retirado de <http://www.sueddeutsche.de/wirtschaft/2.220/europa-sand-im-getriebe-1.2532119> [acedido a 10.02.2018].

Hacker, B. (2011). Konturen einer politischen Union. Berlin: Friedrich Ebert Stiftung. Retirado de <http://library.fes.de/pdf-files/id/ipa/08542.pdf.

Höpner, M. (2013). Die Verschiedenheit der europäischen Lohnregime und ihr Beitrag zur Eurokrise. MPIfG Discussion Paper, 13 (5).

Juncker, J., Tusk, D., Dijsselbloem, J., Draghi, M. \& Schulz, M. (2015, June). Completing Europe's Economic and Monetary Union. A Report by Jean-Claude Juncker in close cooperation with Donald Tusk, Jeroem Dijsselbloem, Mario Draghi, and Martin Schulz (4-5). Brussels, Belgium: European Comission.

Kosters, W., Neumann, M., Ohr, R. \& Vaubel, R. (1998, February 9). Zweites Manifest der Euroskeptiker. Frankfurter Allgemeine Zeitung.

Maatsch, A. (2017). Effectiveness of the European Semester. Explaining Domestic Consent and Contestation. MPIfG Discussion Paper, 17(6).

Majone, G. (1998). Europe's Democratic Deficit. The Question of Standards. European Law Journal, 4(1), 5-28.

Mundell, R. (1961). A Theory of Optimum Currency Areas. The American Economic Review, 51(4), 657-665.

Nars, J. \& Nienaber, M. (2018, January 17). Germany demands clarity on risk reduction for banking Union. Reuters. Retirado de <https://www.reuters.com/article/us-eurozone-germany/germany-demands-clarity-on-risk-reduction-for-banking-union-idUSKBN1F62N1>. [acedido a 17.01.2018]. 
Regulamento (UE) N. 575/2013 do Parlamento Europeu e do Conselho, 26 de junho de 2013, relativo aos requisitos prudenciais para as instituições de crédito e para as empresas de investimento e que altera o Regulamento (UE) n. 648/2012. Jornal Oficial da União Europeia, L 176/1.

Rodl, F. \& Callsen, R. (2014). The Struggle for Union Rights Under the Euro and the Dialects of Social Integration. In Glinski, C. \& Joerges, C, The European Crisis and the Transformation of European Governance (pp. 101-121). Oxford and Portland, USA: Hart.

Rompuy, H. (2012, December 5). Towards a Genuine Economic and Monetary Union. In collaboration with José Manuel Barroso, Jean-Claude Juncker, Mario Draghi. Brussels, Belgium: European Council.

Thompson, H. (2015). Germany and the Euro-Zone Crisis: The European Reformation of the German Banking Crisis and the Future of the Euro. New Political Economy, 20(6), 851-870.

Tilford, S. (2010, September). How to Save the Euro. Centre for European Reform.

\section{Sobre o autor}

GABRIELE DE ANGElis é doutorado pela Sant’Anna School of Advanced Studies (Pisa, Itália) e com uma Grundständige Promotion na Ruprecht-Karls-Universität de Heidelberg (Alemanha). É um filosofo da política e trabalha como investigador na Universidade NOVA de Lisboa. A sua pesquisa verte sobre a legitimidade política da União Económica e Monetária da União Europeia e, em geral, dos sistemas europeus de governança, na perspectiva das reformas discutidas ao nível comunitário. É autor de numerosas publicações que incluem artigos, monografias, organização de livros e números especiais de revistas internacionais sobre tópicos da legitimidade política em contextos nacionais e internacionais, e história do pensamento político.

\section{About the author}

GAbriele De ANGelis PhD from Sant'Anna School of Advanced Studies (Pisa, Italy, 2003), holds a Grundständige Promotion from Ruprecht-Karls-Universität Heidelberg, 1999. He is a political theorist and works as a researcher at the Universidade NOVA de Lisboa. His current research is focused on the reform of the economic governance in the European Union, especially with regard to normative aspects. Author of several papers, monographs, edited volumes, and special issues of international journals on political legitimacy in national and supranational contexts and on the history of political thought. 